American Journal of Infectious Diseases 2 (1): 36-38, 2006

ISSN 1553-619X

(C) 2006 Science Publications

\title{
Hepatitis, Meningitis and Hydrocephalus Caused by Herpes Simplex Virus Type I
}

\author{
${ }^{1}$ Miguel A Pina, ${ }^{2}$ Pedro J Modrego and ${ }^{3}$ F Galve \\ ${ }^{1}$ Neurology Unit, Hospital Obispo Polanco, Teruel, Spain \\ ${ }^{2}$ Department of Neurology, Miguel Servet University Hospital, Zaragoza, Spain \\ ${ }^{3}$ Emergences Service, Hospital Obispo Polanco, Teruel, Spain
}

\begin{abstract}
Herpes simplex virus type is the most frequent cause of sporadic and severe encephalitis in western countries. We report the exceptional case of an immunocompetent man aged 51 and who presented with hepatitis and meningitis by herpes simplex virus. Encephalitis responded to acyclovir but hepatitis did not. The patient developed diffuse hydrocephalus that required the appropriate shunt 20 days after being asymptomatic. Several aspects deserve discussion: the clinical onset with meningeal syndrome, the value of the PCR technique for diagnosis and follow-up purposes, the magnetic resonance (MRI) findings, the anicteric hepatitis with reversible cytolysis and persistent coagulation deficit and the hydrocephalus that was due not to direct effect of the virus but to a probable immunological mechanism.
\end{abstract}

Key words: Herpes simplex virus, meningitis, hepatitis, hydrocephalus

\section{INTRODUCION}

Herpes simplex virus (HSV) type I is the most frequent cause of sporadic viral encephalitis in western countries with an incidence of 5 cases per million people and year in our country. This rate is higher than that found in other studies ${ }^{[1]}$. Without treatment the mortality rate may rise to $70 \%$ and only a small number of patients recover completely. Hence, it is important a rapid diagnosis and early treatment with acyclovir which improves prognosis significantly. The International Herpes Management Forum established a guide for diagnosis and treatment of herpetic encephalitis by recommending the PCR test in the CSF as the ideal method for early diagnosis and treatment with acyclovir at a dose of $10 \mathrm{mg} \mathrm{kg}^{-1}$ every 8 hours intravenously during 14-21 days ${ }^{[2]}$.

Acute hepatitis is an infrequent but serious manifestation of herpes simplex virus infection. It has been reported in immunodepressed patients and in immunocompetent people as well. Owing to the good response to acyclovir many authors recommend to treat with acyclovir the immunocompromised patients presenting with hepatitis of unclear cause ${ }^{[3]}$.

Hydrocephalus is a well-recognised complication of tuberculous and bacterial infections of the nervous system and very uncommon in viral infections. It has been reported rarely in meningoencephalitis by $\mathrm{HSV}^{[4]}$ although it can be produced experimentally in laboratory animals by inoculating the virus into the brain $^{[5]}$

We report the exceptional case of an immunocompetent man who presented with meningitis and hepatitis caused by HSV concomitantly.
Case report: Our patient was a 51 year old physician specialised in acupuncture without history of exposure to drugs or toxic substances. He was admitted because of symptoms suggestive of a meningeal syndrome: headache, fever and vomiting during 5 days before admission to hospital. On clinical examination the patient was conscious and had nuchal rigidity and herpetic eruption in the lips and in the nose. The liver was enlarged approximately $3 \mathrm{~cm}$. Standard blood tests revealed a white cell count of 10,900 per $\mathrm{mm}^{[3]}$ with 2,600 being mononuclear. The erythrocyte sedimentation rate was $112 \mathrm{~mm}$ in the first hour. The enzymatic elevation was as follows: AST $172 \mathrm{IU} \mathrm{L}^{-1}$ (normal: 10-33), ALT $68 \mathrm{IU} \mathrm{L}^{-1}$ (normal: 10-38), GGT $246 \mathrm{IU} \mathrm{L}^{-1}$ (normal: 2-46). The coagulation tests disclosed a prothrombinic activity of $41.4 \%$ (normal: $70-120$ ), a fibrinogen rate of $846 \mathrm{mg} \mathrm{dL}^{-1}$ (normal: 150$500)$. An X-ray film of the chest and a computed tomography of the brain were normal. A lumbar puncture disclosed a clear CSF with a normal glucose rate, $300 \mathrm{mg} \mathrm{dL}^{-1}$ of proteins and 100 leucocytes with $85 \%$ of mononuclear forms and a negative examination for bacteria.

In the first 12 hours after admission he developed severe nasal haemorrhage which needed nasal tamponment. After three days of treatment he became asymptomatic without meningeal signs on clinical examination. We kept the patient on acyclovir during 17 days as well as on $\mathrm{K}$ vitamin intravenously for 10 days. A series of serologic tests were done in blood and CSF with negative results: Brucella, Toxoplasma, Epstein-Barr virus (EB), Cytomegalovirus (CMV), varicela-zoster virus (VZV), HIV and borrelia. The culture of the CSF was negative for bacteria, fungi and

Corresponding Author: DR PJ Modrego, Neurology Department, Miguel Servet University Hospital, 50009 Zaragoza, Spain, Fax: 34-976-431718 
Koch bacillus. The PCR test was positive for herpes simplex virus and negative for herpes zoster in the CSF. Conventional T1 and T2 MRI of the brain revealed no abnormalities but in FLAIR sequences we observed bilateral hypersignal in the periventricular area, parietal cortex and occipital cortex (Fig. 1). The EEG neither showed specific abnormalities on the fourth day. The abdominal echography showed enlargement of the liver with increased density suggestive of hapatitis. Serologic tests for hepatitis viruses were also negative. The aminotransferases increased by the fourth day with an AST of $217 \mathrm{IU} \mathrm{L}^{-1}$, an ALT of $123 \mathrm{IU}$ and a GGT of $123 \mathrm{IU} \mathrm{L}^{-1}$. The hepatic enzymes returned to normal after 10 days. However the coagulation disorders did not really improve as the prothrombinic activity remained at $43.7 \%$. Two days before discharge another lumbar puncture disclosed a CSF with 140 lymphocytes $/ \mathrm{mm}^{[3]}$, normal glucose and $280 \mathrm{mg} \mathrm{dL}^{-1}$ of proteins. The CSF cultures were again negative for bacteria and fungi so were the PCR tests for CMV, EB virus, HSV and VZV.

Given the favourable outcome, the patient was discharged 19 days after admission with the diagnosis of hepatitis and meningitis by HSV. Four days after discharge he came back to hospital because disorientation, behavioural disturbances and difficulty to walk. The clinical examination revealed neither fever nor nuchal rigidity but the gait was ataxic. A Computed Tomography of the brain showed diffuse hydrocephalus (Fig. 2). Then the patient underwent an external ventricular drainage which complicated with a right frontal haemorrhage, subdural effusion and decreased consciousness level. A new ventricular drainage was implanted and the CSF cultures were negative again for bacteria, fungi and tuberculous bacillus. The PCR test was negative again for $\mathrm{HSV}$ and Koch bacillus. Coagulation test showed a deficit of factor VII, a TTPA of $38.3 \mathrm{sec}$ and a prothrombinic activity of $19 \%$. We began with treatment for possible tuberculosis (Isoniazid, rifampin, pirazynamide and ethambutol) without success. The neurological situation of the patient worsened in spite of the resorption of the haemorrhage and the control of the hydrocephalus. A new CSF culture revealed an infection by staphylococcus, which was treated with vancomycin. A Computed Tomography carried out 20 days after the second admission showed again diffuse hydrocephalus in a comatose patient with descerebration rigidity and severe abnormalities on the EEG. The possibility of catheter replacement was dismissed and the patient died from probable cerebral herniation.

The family of the patient denied permission to perform necropsy.

\section{DISCUSSION}

The CNS infections by HSV usually present as encephalitis and less frequently as meningitis with fever

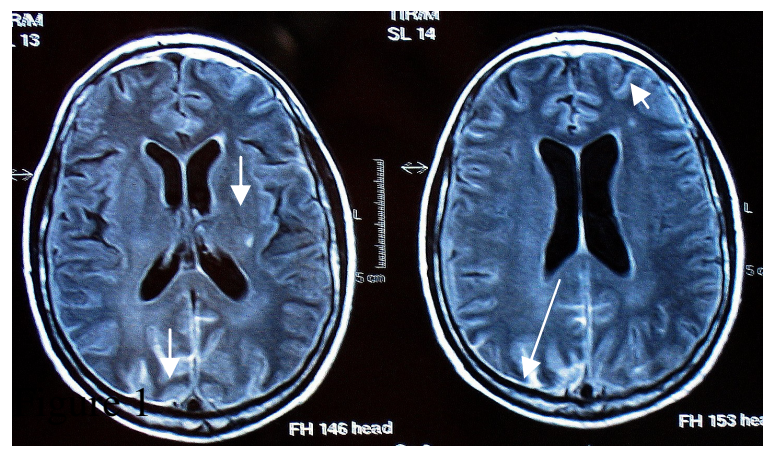

Fig. 1: T1-weighted MRI with FLAIR sequence showing a gyriform hypersignal in both posterior parietal cortices and periventricular hyperintensity (arrows)

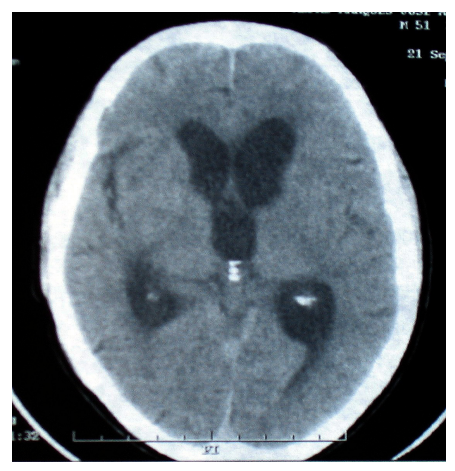

Fig. 2a

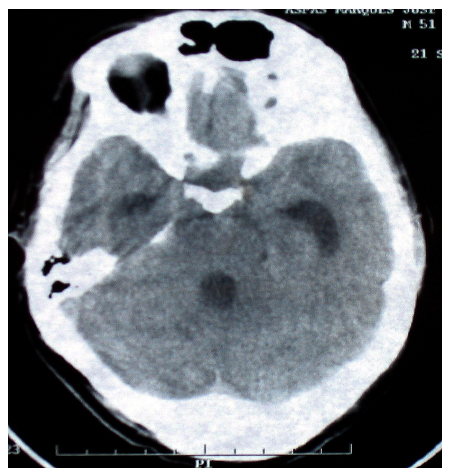

Fig. $2 b$

Fig. 2: Computed Tomography showing diffuse hydrocephalus

and headache. The prognosis is much better in the meningeal forms ${ }^{[6]}$. In this case the meningeal involvement was predominant as it was suggested by symptoms, clinical examination and ancillary tests. On admission the blisters seen in the lips and nose led to the presumptive diagnosis of meningitis by HSV. Some authors have observed that in experimental mice models the infection of nasal cavities spreads efficiently to the $\mathrm{CNS}^{[7]}$.

The diagnosis of HSV is currently made by the PCR technique that demonstrates the presence of viral DNA in the CSF. After appropriate treatment the viral load decreases and the PCR became negative and thus, it may be useful to evaluate efficacy of treatment ${ }^{[2,8]}$. 
Some authors do not regard this technique as necessary if the CSF is normal although its negativity does not exclude at all the diagnosis of HSV encephalitis ${ }^{[9]}$. In our case the PCR technique was made on three occasions in the CSF: immediately after admission, after completion of treatment and when the patient developed hydrocephalus. In the second and third occasions the PCR was negative and this suggests efficacy of treatment and that hydrocephalus was not caused by viral replication.

Hepatitis by HSV is an infrequent severe condition but amenable to treatment. The certainty of diagnosis can only be achieved by means of hepatic biopsy ${ }^{[11]}$. In $70 \%$ of cases it is accompanied by mucocutaneous involvement, which may lead to diagnosis and prompt treatment with acyclovir ${ }^{[12]}$. Hepatic involvement may result in rapid necrosis and severe disorders of coagulation and dead ${ }^{[13,14]}$. Our patient presented with meningitis and hepatitis by HSV simultaneously on the basis of all ancillary studies we carried out. We did not consider hepatic biopsy as strictly necessary because of the negativity of serologic tests for specific hepatitis viruses and the severe coagulopathy. The rate of aminotransferases returned to normal but coagulation disorders did not resolve with treatment and remained until death. The deficit of factor VII we encountered was also reported by other authors ${ }^{[14]}$.

Hydrocephalus has been rarely reported in the HSV encephalitis, in most cases triventricular and in children, although it has also been demonstrated in animal models ${ }^{[4,15,16]}$. In this patient the hydrocephalus was diffuse and appeared 20 days after becoming asymptomatic and apparent resolution of the encephalitis as PCR for HSV was negative. This fact points to an immunological origin of the hydrocephalus and not to a reactivation of the infection. Experimentally in mice inoculated with the virus it has been demonstrated that cyclophosphamide prevents the development of hydrocephalus ${ }^{[5]}$.

We conclude that HSV may cause meningitis and hepatitis concomitantly and without temporal lobe involvement. Hydrocephalus seems to be an uncommon immunomediated complication that worsens prognosis.

\section{REFERENCES}

1. García-Bardeci, D., M.J. Pena, P. Suarez-Bordon, Y. Aladro, C. Pérez-González and B. Lafarga, 2004. Value of the polymerase chaín reaction in the diagnosis of herpes infections of the nervous system. Enferm. Infec. Microbiol. Clin., 22: 150155.

2. Tyler, K.L., 2004. Herpes simplex virus infections of the central nervous system: encephalitis and meningitis, including Mollaret's. Herpes, 11(Suppl 2): 57A-64A.

3. Sevilla, J., S. Fernández-Plaza, M. González-Vicent, I. Colmenero, J.M. Echevarría, A. Pérez and M.A. Díaz et al., 2004. Fatal hepatic failure secondary to acute herpes simplex virus infection. J. Pediatr. Hematol. Oncol., 26: 686-688.
4. Tyagi, A., P. Chumas and C. Ferrie, 2001. Obstructive hydrocephalus following herpes simplex virus type 1 encephalitis treated by repeated third ventriculostomy. Pediatr. Neurosurg., 34: 244-246.

5. Hayashi, K., Y. Iwasaki and K. Yanagi, 1986. Herpes simples virus type 1-induced hidrocephalus in mice. J Virol., 57: 942-951.

6. Vermersch, P. and D. Caparros-Lefebvre, 1997. Encéphalites d'origine virale. Encycl Med Chir (Elsevier, Paris), Neurologie, pp : 12 .

7. Broberg, E.K., J. Peltoniemi, M. Nygardas, T. Vahlberg, M. Rotta and V. Hukkanen, 2004. Spread and replication of and immune response to gamma 134.5-negative herpes simplex virus type 1 vectors in BALB/c mice. J. Virol., 78: 1313913152.

8. Kamei, S., T. Takasu, T. Morishima and T. Mizutani, 2004. Serial changes of intrathecal viral loads evaluated by chemiluminescence assay and nested PCR with acyclovir treatment in herpes simplex virus encephalitis. Intern. Med., 43: 796801.

9. Weil, A.A., C.A. Glaser, Z. Amad and B. Forghani, 2002. Patients with suspected herpes simplex encephalitis: rethinking an initial negative polymerase chain reaction result. Clin. Infect. Dis., 34: 1154-1157.

10. Kuker, W., T. Nagele, F. Schmidt, S. Heckl and U. Herrlinger, 2004. Diffusion-weighted MRI in herpes simplex encephalitis: a report of three cases. Neuroradiology, 46: 122-125.

11. Pinna, A.D., J. Rakela, A.J. Demetris and J.J. Fung, 2002. Five cases of fulminant hepatitis due to herpes simplex virus in adults. Dig. Dis. Sci., 47: 750-754.

12. Sharma, S. and M. Mosunjac, 2004. Herpes simplex hepatitis in adults: a search for mucocutaneous clues. J. Clin. Gastroenterol., 38: 697704.

13. Young, E.J., E. Chafizadeh, V.L. Oliveira and R.M. Genta, 1996. Disseminated herpesvirus infection during pregnancy. Clin. Infect. Dis., 22: 51-58.

14. Sutherland, M.R., H.M. Friedman and E.L. Pryzdial, 2004. Herpes simplex virus type 1encoded glycoprotein $\mathrm{C}$ enhances coagulation factor VIIa activity on the virus. Thromb. Haemost., 92: 947-955.

15. Malm, G., M. Forsgren, M. el Azazi and A. Persson, 1991. A follow-up study of children with neonatal herpes simples virus infections with particular regard to late nervous disturbances. Acta Pediatr. Scand., 80: 226-234.

16. Schinazi, R.F. and X. Yao, 1995. Hydrocephalus induction in mice infected with herpes simplex virus type 2 after antiviral treatment. Antiviral Res., 28: 291-302. 